\title{
ضرورةُ الوعي بالواقع وأهميتُه في فهم النصوص
}

تهدف كلمـة التحرير هلذا العدد مـن بحلة "إسلامية المعرفة" إلى تسليط الضوء على أهمية فقه الواقع، والوعي بمكوناته ومتطلباته، من أجل تحقيق الفهم الصحيح للنصوص

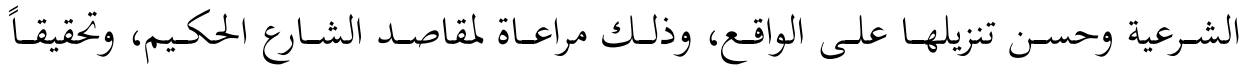

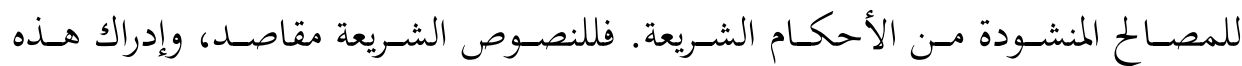
المقاصد، يتطلب أموراً منها:

أولاً: فهم جزئيات الأحكام على ضوء كلياتا وبالعكس؛ بمعنى ضرورة الالتفات إلى

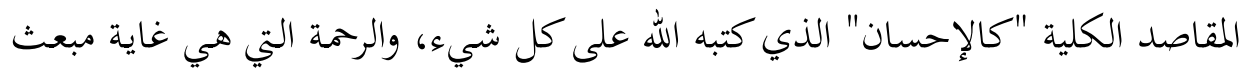

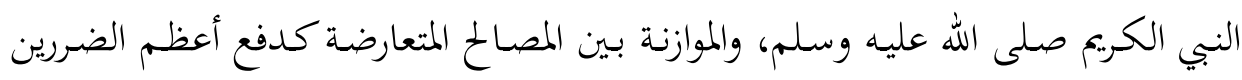

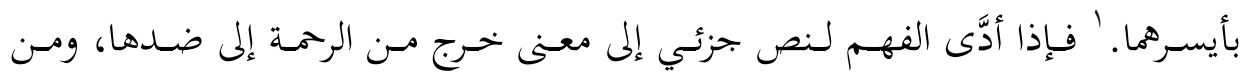

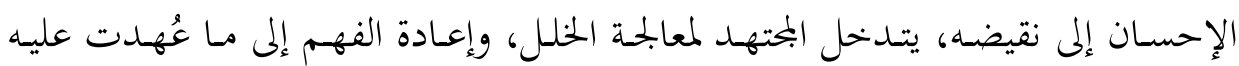
المشروعات.

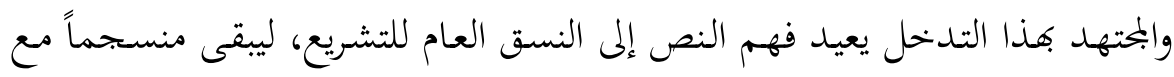

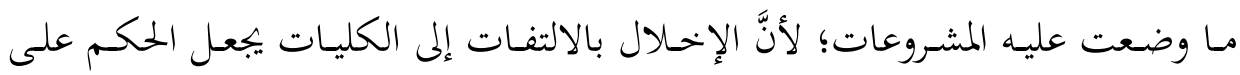

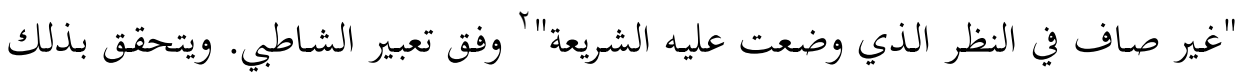
ما يسميه الدريني: "الوحدة الموضوعية" المهيمنة على التشريع كله.

ثانياً: خهبرة معرفية بـالواقع وقوانينه والسنن الاجتماعية، فضـلاً عن الخبرة الأصولية

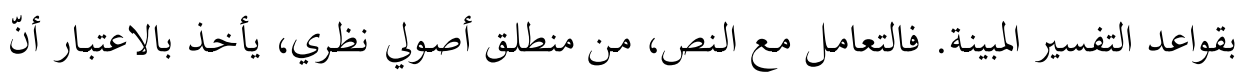

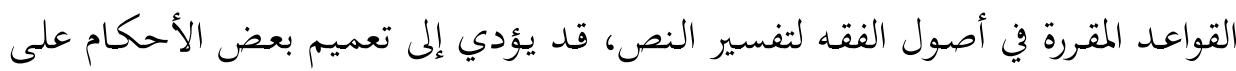


وإدراكه لقوانينه، يمكنه من فهم النص على نحو أقرب لتحقيق مقاصد المشرع. ويتضح

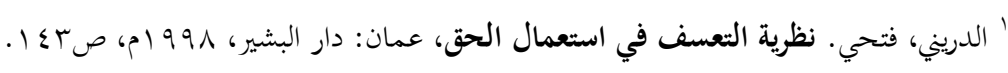

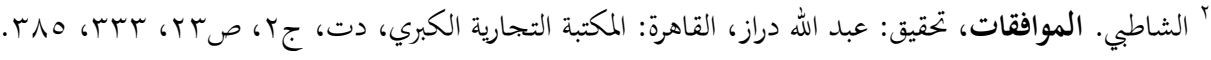


هـذا بجـاء في دراسـة أحكـام النظـام السياسي والعلاقـات الدوليـة؛ ففـي بحـال النظـام

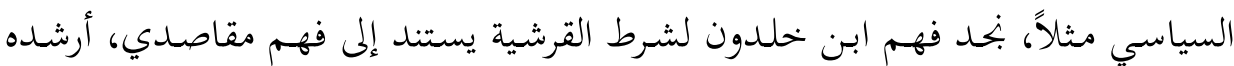
إليه تفاعله مع الواقع، والوعي لما يجتاجه الحكم السليم من شرعية قوامها الرضا والقبول

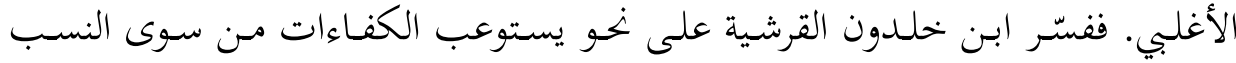
القرشي؛ إذ فسرها بالعصبية، وهي تتحقق اليوم بالقبول الأغلبي. وتفسـير ابـنِ خلـدون أقرب للرؤيـة الإسـلامية الكليـة؛ لأن الكفــاءةَ والجــدارة غـير


ومسن شـأن هـذا المـنهج أن يمكّن الفقيه مـن امـتلاك مهـارة التفكير السـني، لإقـدار

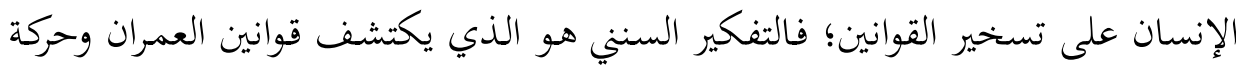

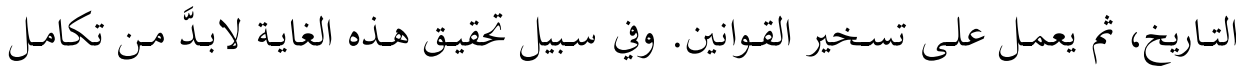

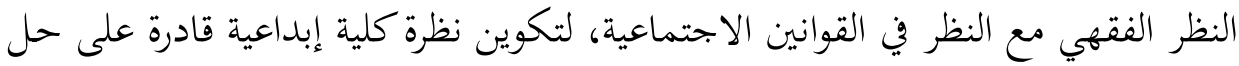
المشكلات، وتسخير الأكوان.

إن تدريب العقل على فهم السنن الكونية والاجتماعية هو من تزكية العقل،

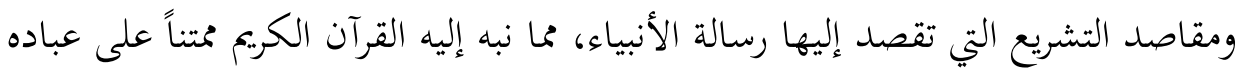



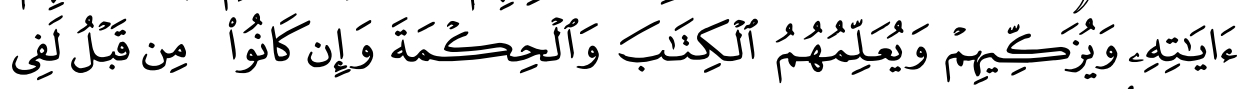

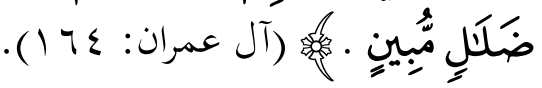

وتأسيساً على ما سبق فالفهم المصلحي لا بدّ أن يرتكز إلى فهم الواقع الذي يطبق



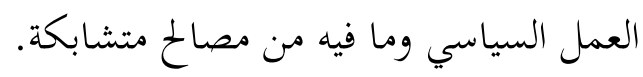

ويُعـد الحكـم الشـعي الواجـب التطبيق هو نتـاج الموازنـة بين دليل الأصل، والـدليل

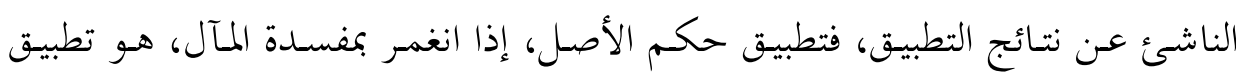
" مذا جزء من حديث طويل أخرجه الإمام مسلم، انظر:

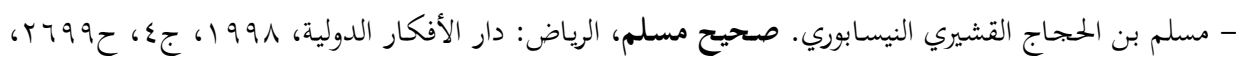






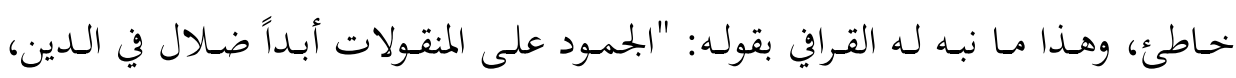

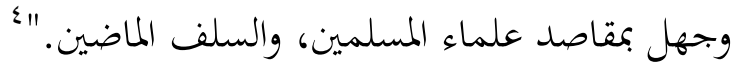

\section{نماذج للأحكام المتغيرة تبعاً لتغير المصالح}

ا ـ اختلاف الفقهاء في وجوب الجهاد الكفائي، هـل هو في كل عـام مرة؟ أم هو

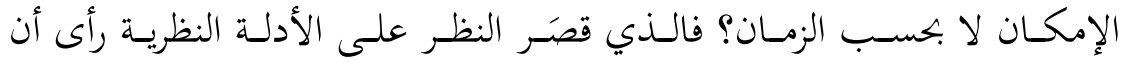

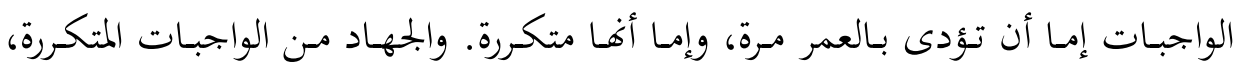

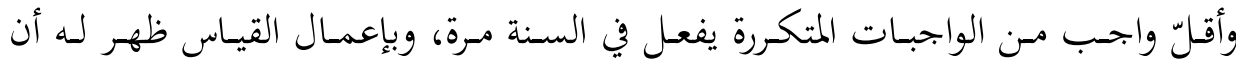

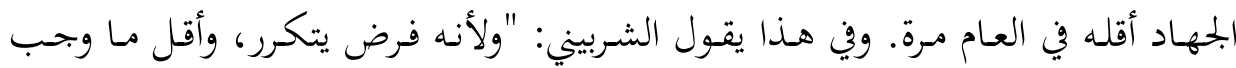

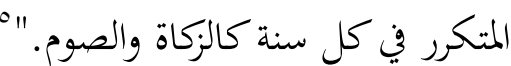

وأما من تفاعل مع الواقع وجمع بين الخبرة العملية وفهم الأدلة النظرية، فقد أدرك أن

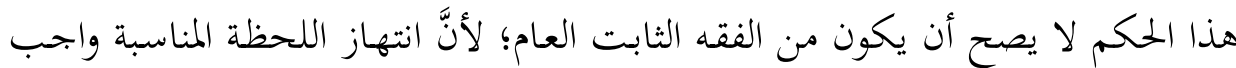

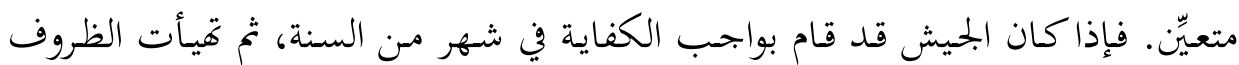

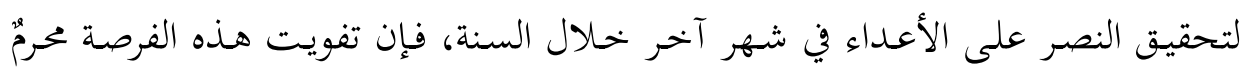

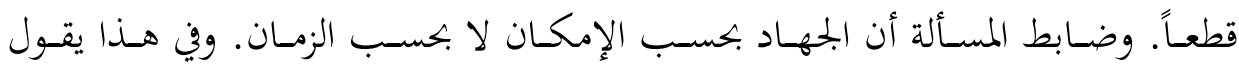

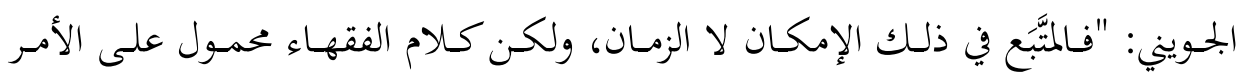

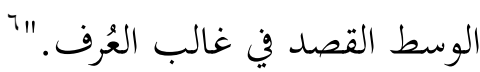

غير أن ما ذكره الفقهاء من وجوب الجهاد في كل عام محمول على الأعم الأغلب،

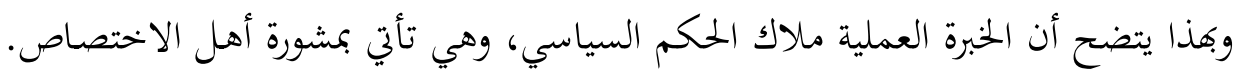

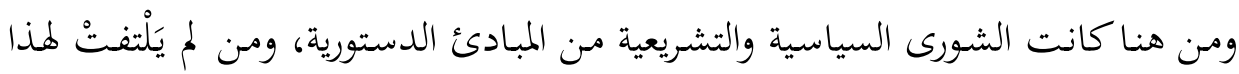

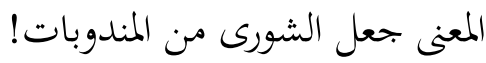

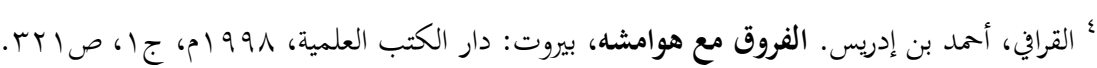

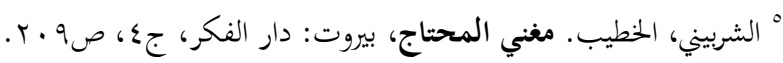

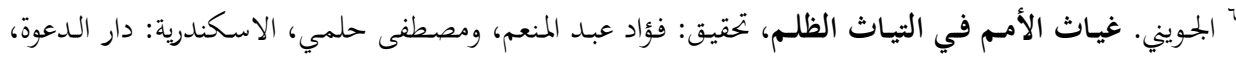


ץ. اختـلاف عـدد مـ المعاصرين مع الفقـه القـديم في تقسيم الدول إلى دار إسـلام

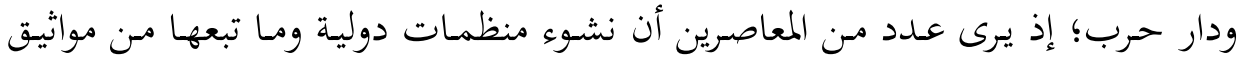

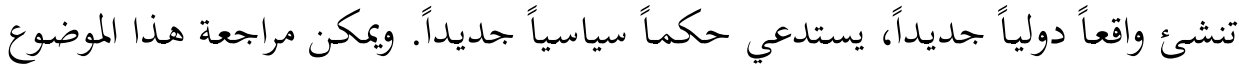

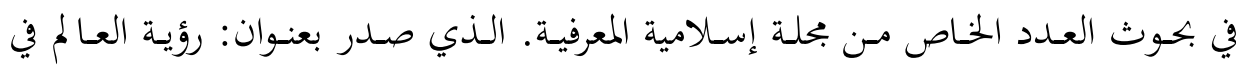



ץ. يمكـن للدولة المسلمة أن تتحالف بـأحلاف عسـكرية مع دول غير مسلمة، إذا

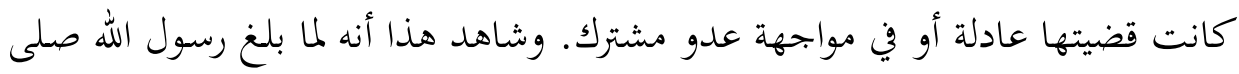

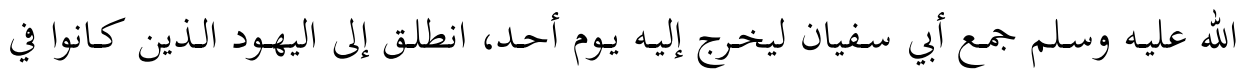

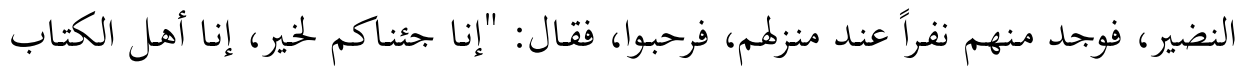

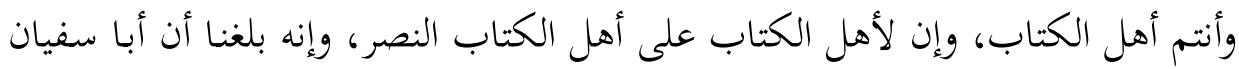

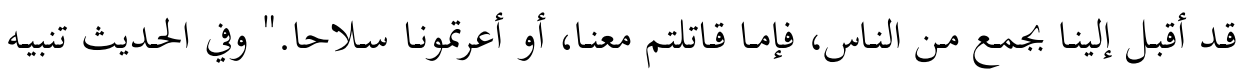

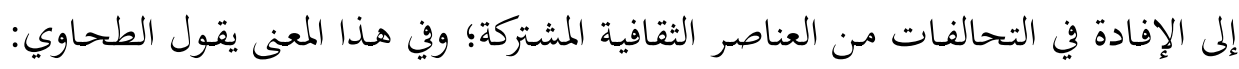

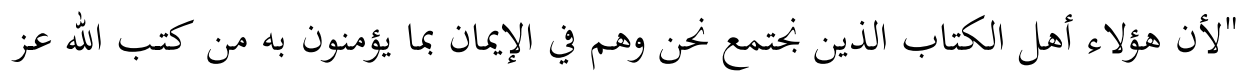

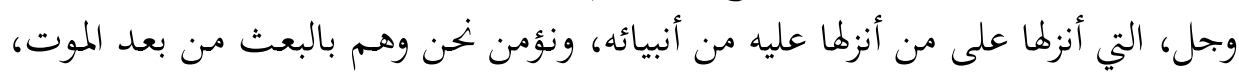

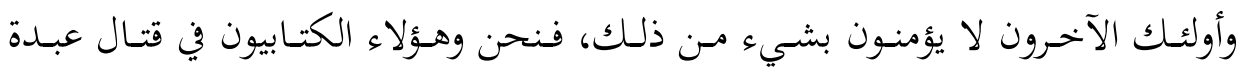

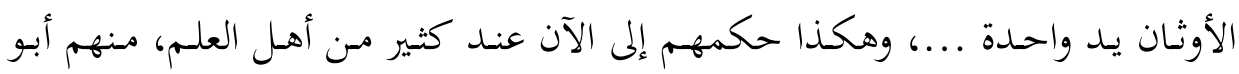

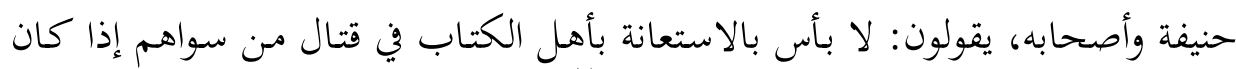

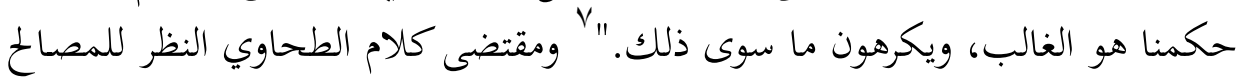

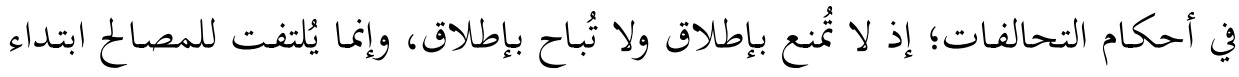

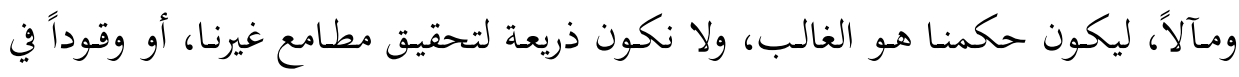

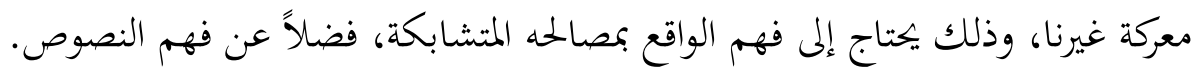

\section{الوعي بالواقع المتغير لا يدركه كل فقيه}

وهــا الوعي بـالواقع المتغير لا يدركهـ كل عـالم وفقيـه، وإنمـا يدركـه مـن تأهَّـل لفهـم

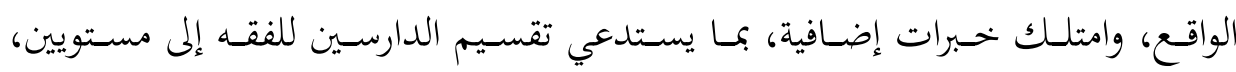



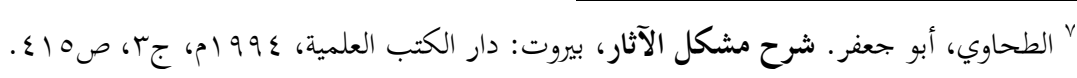


والمستوى الثاني: القادر على توضيح الحق وبيان الحكم الفقهي في القضايا التي تتشابك


جاء في تفسير الطبري "الربانيون فوق الأحبار؛ لأن"الأحبارَ" هـم العلماء، و "الرباني"

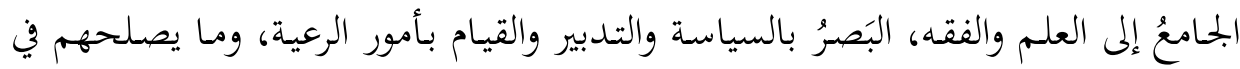

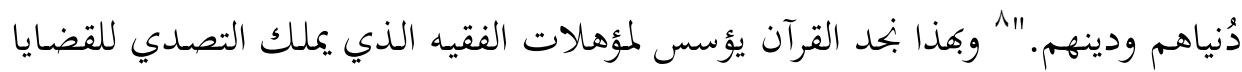

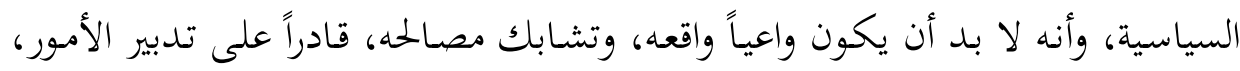

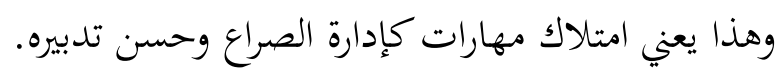

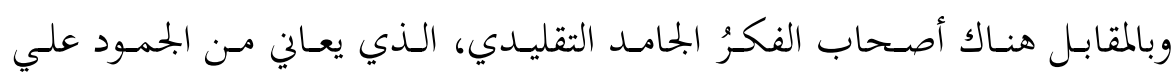

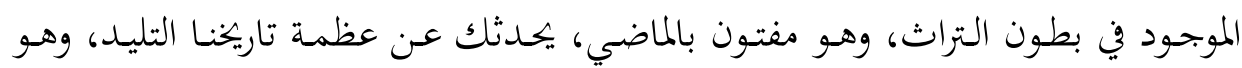

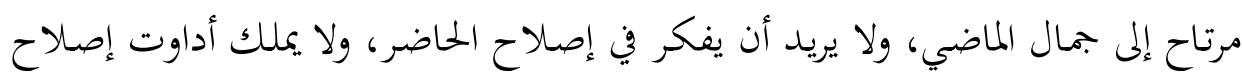


النوع الأول: فكرٌ قِبلَ بقسمة ضيزى بين الحاكم وعلماء الأمة، فترك للحاكم تنظيم

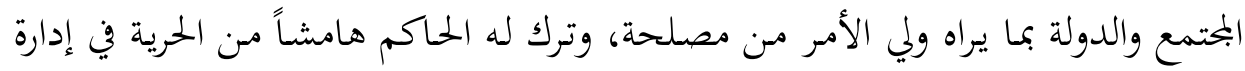

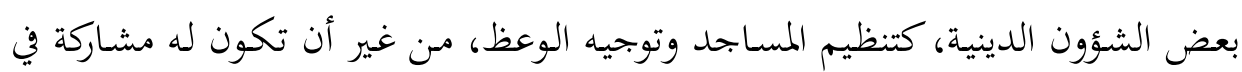

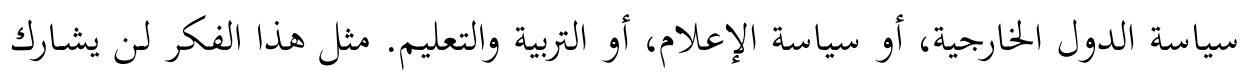

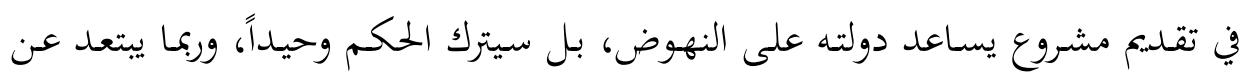

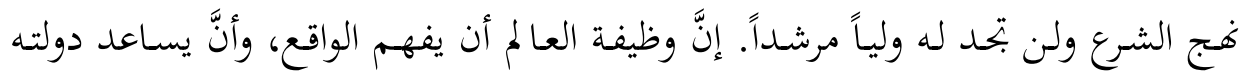
على تقديم برامج تحقق مصالحها، ولا تتصادم مع مصالح الأمة وعقيدتها. أمـا النوع الثاني فهو: فكرٌ أراد استنساخ الماضي دون وعي للتطور والواقعِ المتغير.



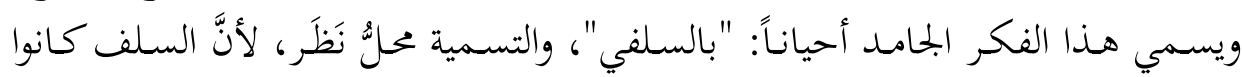

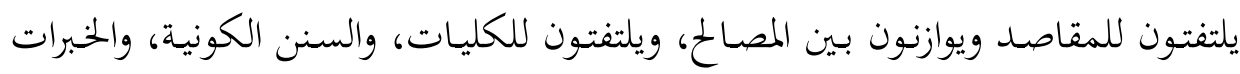
المفيدة عند الأمم الأخرى، كما فعل عمر بن الخطاب حين بين أنشأ الدواوين. ^الطبري، محمد بن جرير. تفسير الطبري، تحقيق: أحمد محمد شاكر، بيروت: مؤسسة الرسالة، ... بم، جج، 
فإذا أردنا النهضة والفهم المصلحي، فلا يصح التطبيق الآلي للنص من غير التفات

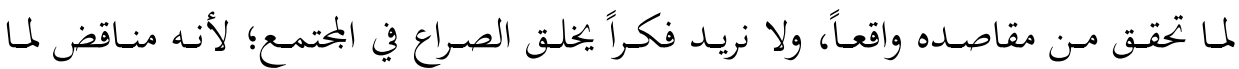


النهوض، ويوحِّد الأمة، ويحشد الطاقات.

سيجد قـارئ بحوث هـذا العـدد أن ثمـة مقاربـة مقاصدية تأخـذ بعين الاعتبـار أهمية

الوعي بفهم الواقع لتفعيل النص الديني، وضرورة استيعاب المنجز الحضاري والفكري من

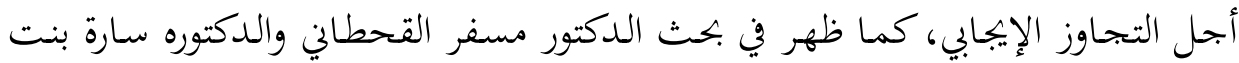

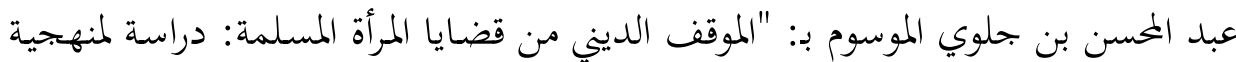



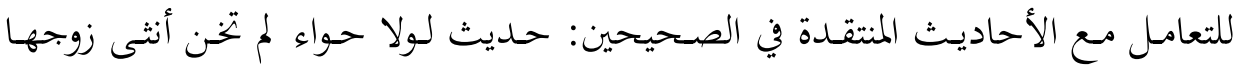
نموذجاً"، أن يكون رؤية نقدية للخلل في بعض أوجه التعامل مع السنة النبوية الشريفة،

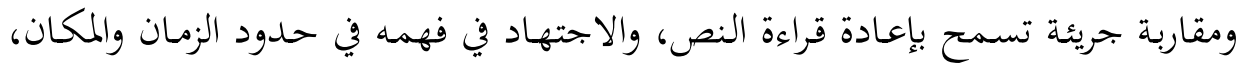

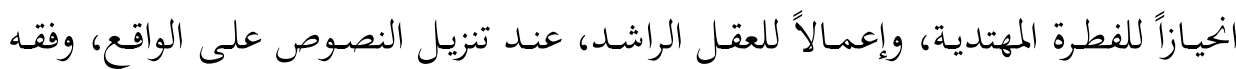
الأحوال المتغيرة والمستجدات.

وثمة مقاربة منهجية تحاور العقل المسلم في قدرته على النقد الحر والعلمي لتعامله مع الـذات، والكشـف عـن أسـس قوتـه المنهجيـة وبتحليـات المنهجيـة العلميـة في تنظيراتـهـ



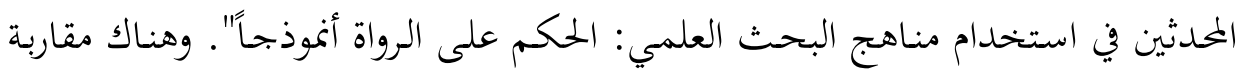

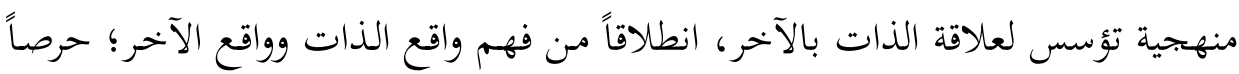

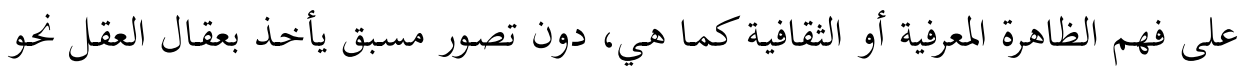



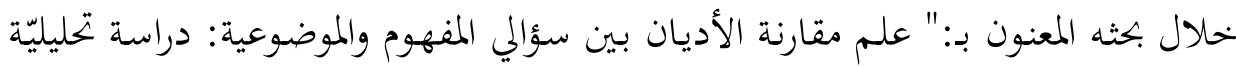

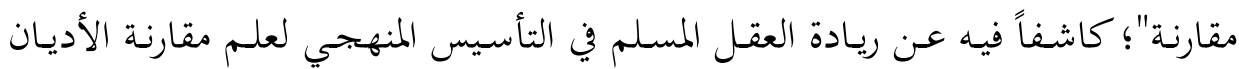
بصورته المنهجية العلمية. والله من وراء القصد وهو يهدي السبيل. 